\title{
Effect of smoking on the survival of dental implants
}

\author{
Aline Satie Takamiya, Marcelo Coelho Goiato, Humberto Gennari Filho
}

\begin{abstract}
Background. Although the long-term success of implant treatment has been well- established, failures can still occur and the smoking habit has been reported as a risk factor for implant loss. A literature review on the effects of smoking on the survival of dental implants was undertaken.

Methods and Results. Medline database was used to carry out the review with the keywords "osseointegration", "smoking" and "bone healing". The cigarette has more than 4,000 bioactive chemical components with potential toxic effects to human tissues including bone. Nicotine is the main component of the cigarette and it is frequently associated with bone healing failures. Since smoking negatively affects the osseointegration of dental implants, the main target is to quit the consumption of cigarettes.

Conclusion. Nevertheless, the smoking habit should not be an absolute contraindication for implant treatment, but, patients should be advised that they are at a greater risk of implant failure.
\end{abstract}

Key words: smoking, bone healing, osseointegration, dental implants

Received: July 23, 2012; Accepted: May 3, 2013; Available online: May 27, 2013

http://dx.doi.org/10.5507/bp.2013.037

Department of Dental Materials and Prosthodontics, Araçatuba Dental School, University of State of Sao Paulo, Araçatuba, Sao Paulo, Brazil Corresponding author: Marcelo Coelho Goiato, e-mail: goiato@foa.unesp.br

\section{INTRODUCTION}

The long-term success of implant treatment has been reported by several authors ${ }^{1-5}$. As a result, the prosthetic rehabilitation with dental implants has become essential in clinical therapy ${ }^{6}$. However, implant failures are still prone to occur and are considered a problem for both patient and dentist ${ }^{1}$.

The risk factors for surgical implant failures can be divided into two categories. The first is related to the surgical technique, implant type and place, waiting time between tooth extraction and implant insertion, and between implant insertion and loading. The second consists in patient characteristics such as uncontrolled diabetes, alcohol consumption and smoking?

In the oral cavity, the smoking habit is associated with delayed bone healing, reduced bone height, increased rate of bone loss, formation of poor quality bone as well as increased incidence of peri-implantites ${ }^{8-14}$.

Smokers present 1.69 times higher chances of implant failures than non-smokers during the first implant surgical stage (before prosthesis insertion). The smoking habit has also been associated with delayed failures of dental implants such as those occurring during the second implant surgical stage ${ }^{6,7}$. Additionally, a multivariate survival analysis showed that short implants and implant placement in the maxilla were additional independent risk factors for implant failure ${ }^{6}$.

It has also been reported that the duration and number of cigarettes smoked can affect the peri-implant bone tissue $^{6,15,16}$. Several studies advocated that smoking affects cellular proliferation and increases gingival fibroblast cytotoxicity. In one study, nicotine $(200 \mu \mathrm{g} / \mathrm{mL})$ reduced by $50 \%$ cellular proliferation ${ }^{17}$.
DeLuca et al. ${ }^{6}$ evaluated the survival rate of dental implants in 464 patients over 10 years. The overall implant failure rate was $7.72 \%$. Patients who were smokers at the time of implant surgery had significantly higher implant failure rate $(23.08 \%)$ than non-smokers $(13.33 \%)$.

Nevertheless, the mechanism in which the tobacco affects the osseointegration and the survival of implants remains unknown ${ }^{18}$. Failures generally occur due to the deposition of fibrous tissue at the bone-implant interface ${ }^{7}$. The implant insertion may be compared to the healing process after bone fracture. Initially, the coagula is formed between the implant and bone tissue. Depending on the local conditions, and the presence of relative immobility of the implant, pluripotent mesenchymal cells differentiate into osteoblasts and fibroblasts, and a healing and bone tissues are formed. The presence of cigarette components affects this process ${ }^{7}$.

For this reason, as the use of dental implants to rehabilitate edentulous patients has become widespread and the use of cigarettes is considered one of the main factors in implant failures, it is essential to understand the role of smoking on the peri-implant bone healing. A literature review concerning the osseointegration and smoking habit was performed based on papers published in the last 24 years.

\section{METHODS}

Medline database was used to carry out the review with the keywords "osseointegration", "smoking" and "bone healing". Initially, no exclusion criterion was applied. After reading the title and abstract of all articles, a total of 41 studies were selected. For the inclusion criteria, 
original and review articles about osseointegration, bone healing, smoking habit and implant failure were used, and the others were excluded.

\section{LITERATURE REVIEW AND DISCUSSION}

Bain and $\mathrm{Moy}^{9}$ reported the effect of cigarettes on the survival rate of implants. Smokers had an $11.28 \%$ of implant failures while non-smokers exhibited $4.76 \%$ failures. Lambert et al. ${ }^{19}$ claimed that after a 3-year period of implant insertion, smokers presented 1.5 times greater failures than non-smokers. However, both groups exhibited high rate of implant success (94\% and $91.1 \%$, respectively).

Several animal studies have shown the negative effect of tobacco on the healing process around dental implants ${ }^{14}$. Correa et al. ${ }^{20}$ evaluated the influence of smoking on the implant osseointegration placed in rabbits' tibia that were exposed to intermittent inhalation of cigarette smoke. The smoking negatively affected the density and quantity of bone formed around the implant after 60 days of implant insertion. The authors pointed out that these effects may be more pronounced in the oral cavity of smokers due to the presence of cigarette particles, heating and great concentration of toxic components ${ }^{9,20-23}$.

Stefani et al. ${ }^{24}$ in an animal study investigated the effect of nicotine on the peri-implant bone healing of implants inserted in rabbits and showed that the daily administration of $0.93 \mathrm{mg} / \mathrm{kg}$ of nicotine significantly decreased the percentage of bone-implant contact after 42 days of implant insertion.

Cesar-Neto et al. ${ }^{13}$ evaluated the impact of nicotine and cigarette inhalation on the osseointegration of titanium implants. Animals were subjected to cigarette smoke inhalation and subcutaneous administration of nicotine over 60 days. Cigarette smoke inhalation had a negative influence on the bone-implant contact and quantity of bone in the implant screws. However, the nicotine administration did not influence either parameter.

These findings are in accordance with those reported by Balatsouka et al. ${ }^{16}$ who investigated the influence of systemic administration of high doses of nicotine on the osseointegration of implants inserted into rabbits' tibia. Nicotine did not affect the initial phase of osseointegration, which suggests that other components are involved in the failure of dental implants of smokers.

Gotfredsen et al. ${ }^{25}$ also reported that the administration of nicotine over 6 months did not influence the bone healing and osseointegration of dental implants inserted in rabbits. Stefani et al. ${ }^{24}$ claimed that the nicotine isolated is not responsible for implant failures in smokers.

Clinical studies strongly suggested that the local exposition of the peri-implant tissue to the cigarette components contributes to the high prevalence of implant failures in smokers ${ }^{6,18,26,27}$. This may be due to the high levels of cigarette components in the oral fluids of smokers $^{28,29}$ as well as the presence of such substances in the bone-implant interface ${ }^{18}$.
The cigarette has more than 4,000 bioactive chemical components with potential deleterious effect to human tissues including bone ${ }^{14,18,30}$. The nitrosamines, aldehydes, carbon monoxide, carbon dioxide, ammonia and benzene are components of the cigarette that may affect the bone healing process. Carbon monoxide is a competitor/inhibitor of the oxygen and decreases the oxygen carrying capacity of red blood cells; the hydrogen cyanide promotes hypoxia by inhibiting the enzyme systems necessary for metabolism oxidation ${ }^{7,13,15,17,21,31}$.

Additionally, smoking is associated to the increased concentration of reactive oxygen and reduced levels of vitamins $^{32}$. Previous studies have correlated high levels of reactive oxygen with bone resorption process which may explain in part the negative effect of smoking on the osseointegration process ${ }^{33,34}$

On the other hand, nicotine is the main component of the cigarette and it is found in the plasma and saliva of smokers in a concentration of 4 to $73 \mathrm{ng} / \mathrm{mL}$ and 96 to $1.6 \mathrm{mg} / \mathrm{mL}$, respectively ${ }^{18,28,29,35}$. Nicotine has high diffusion potential and has been associated with deleterious effect on the bone healing ${ }^{18}$. The osseointegration process requires the recruitment of osteoblasts, their anchorage, adhesion, spreading, proliferation and differentiation into osteoblasts that secrete extracellular matrix calcification on the implant surface. All these cellular events are sensitive to the local and systemic effects of nicotine and other associated components ${ }^{15,16,35,36}$.

In addition, nicotine reduces osteoblastic activity affecting the amount of collagen available to form the extracellular matrix. Nicotine also may induce microvascular obstruction which results in ischemia, and decreases the blood cells proliferation with direct reduction of blood flow and nutrients in the healing area after implant insertion $^{17,31}$.

Considering the high diffusion potential of nicotine and the permeability of the gingival epithelium around dental implants which in some way is structurally and functionally similar to the junctional epithelium found around natural teeth, a direct modulation of the osteoblastic activity may be an additional factor to the overall effect of nicotine on the surrounding bone of dental implants ${ }^{14}$.

In vitro studies have shown that nicotine can also inhibit the defensive function of neutrophils and monocytes and, may stimulate lipopolysaccharide to secrete prostaglandin E2, and may also have deleterious effect on various periodontal cell functions ${ }^{24}$.

Nicotine also decreases the proliferation of macrophages that participate of both specific and non-specific immune response during the acute phase of cellular injury and acts against antigens, cytokines and initiates the immune process. Therefore, when the macrophages function is decreased, the immune response is directly affected and causes increased susceptibility to infections in the surgical area of implant insertion ${ }^{17}$.

Other authors suggest that changes in levels of intracellular calcium ions followed by nicotine binding to its receptors and subsequent activation of voltage-dependent calcium channels can modulate in some way the effect of nicotine on the bone metabolism ${ }^{37}$. 
According to Ohkuma and Poole ${ }^{38}$, nicotine can induce vacuolation of the cytoplasm of cells presented on the surface of dental implants in a dose-dependent way mainly in concentration greater than $0.2 \mathrm{mg} / \mathrm{mL}$. Nicotine also accumulates into the lysosomes through the permeabilization of cell membrane. As the gradient concentration into the lysosomes increases, water penetrates into the cell by osmotic reaction and these structures swell and form large vacuoles. Although the aforementioned mechanism may be detrimental to the osseointegration process, it has been suggested that the presence of nicotine into the lysosomes may also act as a protector mechanism, preventing the interaction of nicotine with other cytoplasmic cellular structures.

Based on the potential effects of smoking to the osseointegration of implants, the most important target to avoid such negative effects would be eliminating the smoking habit. Some studies have reported that both temporary and complete cessation of cigarette consumption and cigarette smoke inhalation can reverse the negative effect of smoking to the bone healing around dental implants ${ }^{13,20}$.

Several clinical studies found no significant difference on the survival of dental implants when comparing nonsmokers (control) and smokers that had stop smoking following a strict protocol. However, Bain and Moy ${ }^{9}$ reported that of 51 patients who had initiated the advised protocol of smoking interruption, just 23 remained smoke free after 1 year period. Even in specialized centers with professional support and use of medicines, the rate of patients who stop smoking in such programs is relatively low ${ }^{20,39}$.

Consequently, the use of implant with surface treatment could decrease the negative impact of smoking on the survival of dental implants, as the implant roughness has a direct effect on the migration, adhesion, proliferation and differentiation of osteoblasts ${ }^{20}$. Correa et al. ${ }^{20}$ compared the effect of smoking on the osseointegration of machined implants and those with aluminum oxide surface treatment. Although the presence of surface treatment increased the bone-implant contact ratio, it was not able to mitigate the effects of smoking on the bone healing process. Stefani et al. ${ }^{24}$ reported that the design of implant surface may have a positive role on the osseointegration of implants inserted in animals subjected to nicotine administration.

D'Ávila et al. ${ }^{40}$ evaluated the effect of surface topography on the survival of implants inserted in the posterior region of maxilla of smokers after two months of healing without loading. The surface treatment with $100-\mu \mathrm{m}$ aluminum oxide particles enhanced the histometric results in smokers. Therefore, simple modification of the implant topography may improve the survival of implants in smok$\mathrm{ers}^{40}$.

Despite the negative effects of smoking for bone healing after implant insertion, cigarette smoking should not be an absolute contraindication for implant treatment. Patients should be advised that they are at greater risk of implant failure if they smoke during the initial healing phase following implant insertion.
For these reasons, patients should be informed that the interruption of smoking is the best option for those who undergo implant treatment.

\section{CONCLUSION}

Based on the present literature review, it was concluded that the smoking habit may represent an additional risk factor for implant therapy; however, cigarette smoking should not be an absolute contraindication for this treatment.

\section{ACKNOWLEDGEMENT}

Authorship contributions: AST: literature search and manuscript writing; HGF: study design; MCG: data interpretation, final approval; all authors contributed equally to the manuscript preparing.

Conflict of interest statement: None declared.

\section{REFERENCES}

1. Branemark PI. Osseointegration and its experimental background. J Prosthet Dent 1983;50:399-410.

2. Lindquist LW, Carlsson GE. Long-term effects on chewing with mandibular fixed prostheses on osseointegrated implants. Acta Odontol Scand 1985;43:39-45.

3. Albrektsson T, Zarb G, Worthington P, Eriksson AR. The long-term efficacy of currently used dental implants: a review and proposed criteria of success. Int J Oral Maxillofac Implants 1986;1:11-25.

4. Zarb GA, Schmitt A. The longitudinal clinical effectiveness of osseointegrated dental implants: the Toronto Study. Part II: The prosthetic results. J Prosthet Dent 1990;64:53-61.

5. DeLuca S, Zarb G. The effect of smoking on osseointegrated dental implants. Part II: Peri-implant bone loss. Int J Prosthodont 2006;19:560-6.

6. DeLuca S, Habsha E, Zarb GA. The effect of smoking on osseointegrated dental implants. Part I: implant survival. Int J Prosthodont 2006;19:491-8.

7. Sverzut AT, Stabile GA, de Moraes M, Mazzonetto R, Moreira RW. The influence of tobacco on early dental implant failure. J Oral Maxillofac Surg 2008;66:1004-9.

8. Meechan JG, Macgregor ID, Rogers SN, Hobson RS, Bate JP, Dennison $M$. The effect of smoking on immediate post-extraction socket filling with blood and on the incidence of painful socket. Br J Oral Maxillofac Surg 1988;26:402-9.

9. Bain CA, Moy PK. The association between the failure of dental implants and cigarette smoking. Int J Oral Maxillofac Implants 1993;8:609-15

10. Bolin A, Eklund G, Frithiof L, Lavstedt S. The effect of changed smoking habits on marginal alveolar bone loss. A longitudinal study. Swed Dent J 1993;17:211-6.

11. Haber J, Wattles J, Crowley M, Mandell R, Joshipura K, Kent RL. Evidence for cigarette smoking as a major risk factor for periodontitis. J Periodontol 1993;64:16-23.

12. Holm G. Smoking as an additional risk for tooth loss. J Periodontol 1994;65:996-1001.

13. Cesar-Neto JB, Duarte PM, Sallum EA, Barbieri D, Moreno H, Jr., Nociti $\mathrm{FH}, \mathrm{Jr}$. A comparative study on the effect of nicotine administration and cigarette smoke inhalation on bone healing around titanium implants. J Periodontol 2003;74:1454-9.

14. Pereira ML, Carvalho JC, Peres F, Gutierres M, Fernandes MH Behaviour of human osteoblastic cells cultured on plasma-sprayed titanium implants in the presence of nicotine. Clin Oral Implants Res 2008;19:582-9. 
15. Schwartz-Arad D, Samet N, Mamlider A. Smoking and complications of endosseous dental implants. J Periodontol 2002;73:153-7.

16. Balatsouka D, Gotfredsen K, Lindh CH, Berglundh T. The impact of nicotine on bone healing and osseointegration. Clin Oral Implants Res 2005;16:268-76.

17. Garg A. Pathophysiology of tobacco use and wound healing. Dent Implantol Update 2010;21:1-4.

18. Pereira ML, Carvalho JC, Peres F, Fernandes MH. Simultaneous effects of nicotine, acrolein, and acetaldehyde on osteogenic-induced bone marrow cells cultured on plasma-sprayed titanium implants. Int Oral Maxillofac Implants 2010;25:112-22.

19. Lambert PM, Morris HF, Ochi S. The influence of smoking on 3-year clinical success of osseointegrated dental implants. Ann Periodontol 2000;5:79-89.

20. Correa MG, Gomes Campos ML, Cesar-Neto JB, Casati MZ, Nociti FH, Sallum EA. Histometric evaluation of bone around titanium implants with different surface treatments in rats exposed to cigarette smoke inhalation. Clin Oral Implants Res 2009;20:588-93.

21. Levin L, Schwartz-Arad D. The effect of cigarette smoking on dental implants and related surgery. Implant Dent 2005;14:357-61.

22. Wang $F$, Lee HP, Lu C. Thermal-mechanical study of functionally graded dental implants with the finite element method. J Biomed Mater Res A 2007;80:146-58.

23. Feuerstein O, Zeichner K, Imbari C, Ormianer Z, Samet N, Weiss El. Temperature changes in dental implants following exposure to hot substances in an ex vivo model. Clin Oral Implants Res 2008;19:62933.

24. Stefani CM, Nogueira F, Sallum EA, de TS, Sallum AW, Nociti FH, Jr. Influence of nicotine administration on different implant surfaces: a histometric study in rabbits. J Periodontol 2002;73:206-12.

25. Gotfredsen K, Lindh CH, Berglundh T. Does longstanding nicotine exposure impair bone healing and osseointegration? An experimental study in rabbits. J Biomed Mater Res B Appl Biomater 2009;91:91823.

26. De Bruyn H, Collaert B. The effect of smoking on early implant failure. Clin Oral Implants Res 1994;5:260-4.

27. Alsaadi G, Quirynen M, Komarek A, van Steenberghe D. Impact of local and systemic factors on the incidence of oral implant failures, up to abutment connection. J Clin Periodontol 2007;34:610-7.
28. Russell MA, Feyerabend C, Cole PV. Plasma nicotine levels after cigarette smoking and chewing nicotine gum. Br Med J 1976;1:1043-6.

29. Hoffmann D, Adams JD. Carcinogenic tobacco-specific $\mathrm{N}$-nitrosamines in snuff and in the saliva of snuff dippers. Cancer Res 1981;41:4305-8.

30. Supervia A, Nogues X, Enjuanes A, Vila J, Mellibovsky L, Serrano S et al. Effect of smoking and smoking cessation on bone mass, bone remodeling, vitamin D, PTH and sex hormones. J Musculoskelet Neuronal Interact 2006;6:234-41.

31. Shibli JA, Piattelli A, lezzi G, Cardoso LA, Onuma T, de Carvalho PS et al. Effect of smoking on early bone healing around oxidized surfaces: a prospective, controlled study in human jaws. J Periodontol 2010;81:575-83.

32. Duthie GG, Arthur JR, James WP. Effects of smoking and vitamin E on blood antioxidant status. Am J Clin Nutr 1991;53:1061S-3S.

33. Garrett IR, Boyce BF, Oreffo RO, Bonewald L, Poser J, Mundy GR. Oxygen-derived free radicals stimulate osteoclastic bone resorption in rodent bone in vitro and in vivo. J Clin Invest 1990;85:632-9.

34. Ries WL, Key LL, Jr., Rodriguiz RM. Nitroblue tetrazolium reduction and bone resorption by osteoclasts in vitro inhibited by a manganese-based superoxide dismutase mimic. J Bone Miner Res 1992; 7:931-9.

35. Pereira ML, Carvalho JC, Peres F, Fernandes MH. Effect of nicotine in matrix mineralization by human bone marrow and Saos- 2 cells cultured on the surface of plasma-sprayed titanium implants. J Biomed Mater Res A 2009;88:84-93.

36. Schwartz Z, Boyan BD. Underlying mechanisms at the bone-biomaterial interface. J Cell Biochem 1994;56:340-7.

37. Yuhara S, Kasagi S, Inoue A, Otsuka E, Hirose S, Hagiwara H. Effects of nicotine on cultured cells suggest that it can influence the formation and resorption of bone. Eur J Pharmacol 1999;383:387-93.

38. Ohkuma S, Poole B. Cytoplasmic vacuolation of mouse peritonea macrophages and the uptake into lysosomes of weakly basic substances. J Cell Biol 1981;90:656-64.

39. Akkaya A, Ozturk O, Cobanoglu H, Bircan HA, Simsek S, Sahin U. Evaluation of patients followed up in a cigarette cessation clinic. Respirology 2006;11:311-6.

40. d'Avila S, dos Reis LD, Piattelli A, Aguiar KC, de Faveri M, Borges FL, lezzi G, Oliveira NT, de G Cardoso LA, Shibli JA. Impact of smoking on human bone apposition at different dental implant surfaces: a histologic study in type IV bone. J Oral Implantol 2010;36:85-90. 